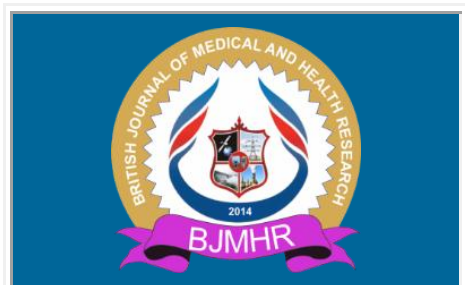

\title{
BJMHR
}

British Journal of Medical and Health Research

Journal home page: www.bjmhr.com

\section{Effectiveness of Class Response System to Increase Attentiveness of Student In Classroom Teaching}

\section{Sanam Anwar}

MD Community Medicine, Head of the Department, Epidemiology \& Public Health, College of Medicine \& Health Sciences, National University of Science and Technology,

Sohar,Oman

\section{ABSTRACT}

The lecture allows very little interaction and feedback from the students. Class Response System (CRS) can have a catalytic effect on teaching with lecture environments moving from silence and passivity towards dialogue and interaction. The present study was conducted to see the effectiveness of increasing the attentiveness of students in classroom theory lectures and to study the students' perception of effectiveness of CRS in improved learning outcome. CRS was used in the lecture classes of Public Health for the undergraduate students of MD program of College of Medicine. Students anonymously clicked answers for the questions displayed on the screen. Correct answers were discusses with instant feedback after the CRS session. Likert scale was used to assess students' opinion on the effectiveness of CRS for better learning. The average percentage of correct responses in the CRS sessions was $77.15 \pm 10.34$. Statistically significantly more number of students got higher grades when CRS was used. $87 \%$ of students agreed that it aroused their interest in the class and $79.7 \%$ said that it made them more attentive during the lecture. $79.1 \%$ agreed that it encouraged discussion over the wrongly answered questions. CRS made the students attentive in the class and created a platform for the students to interact with the teacher and clarify their concepts in the class itself. It helped them in memorizing the key points in the lecture which helped them to recall it even when they studied on their own thereby helping them to get better grades in exams.

Keywords: Class response system, concentration, clickers, perception, students. 


\section{INTRODUCTION}

The Class response system (CRS), the subject of this research, is a technology that consists of eight-button response pads called "clickers" that transmit (infrared signal) student responses to a receiver connected to the instructor computer in the classroom. The system allows the instructor to ask a variety of different question types and record and graphically-display the students' responses in real time and saves the results for later. The main advantages of electronic response system are the anonymity of responses; it can also store response data for future analysis and assessment. This technology has been evolving to meet the needs of the modern classroom $\left.{ }^{1,2}\right]$. CRS is being used in a variety of ways: as a learning strategy to facilitate increased attention, interaction, instruction, student preparation and discussion; to motivate students for attendance and participation; and to provide formative and summative knowledge assessments $\left[^{3}\right]$. There is evidence within the literature that CRS can have a catalytic effect on teaching with lecture environments moving from silence and passivity towards dialogue and interaction $[4,5]$. There is also a suggestion that CRS use facilitates a shift towards learner-centric approaches through reopened channels of communication [ $\left.{ }^{6}\right]$.

For the undergraduate MD program College of Medicine, there is block system for the subject course of Public Health. The passing grade is $70 \%$. The block of Public Health is for continuous three months wherein the students have continuous two theory classes of 1 hour duration each twice a week. All the classes are conducted by using power point presentation in a big lecture hall. It becomes very tiring for the students to attend two consecutive classes of Public Health. It becomes difficult for them to grasp after the attention span of half an hour. It is important to engage them so as to increase their participation and improve their comprehension. It is not difficult to use CRS for the same with the very fact that the college already has the software. A further motivation for the use of CRS was to initiate a deeper interaction with students during lectures in a large cohort setting $\left[^{7}\right]$. CRS encourages students as their participation is concealed from others $\left[^{8}\right]$. Historically, other systems have been used such as colored flashcards, but the current computerized systems are unrivalled in their speed of data collection, quality of data presentation and most importantly, their confidentiality and anonymity of student response $\left[{ }^{9}\right]$. The lecture has been classed as impersonal $\left[{ }^{6}\right]$ or allowing very little in the form of feedback from the students $\left[{ }^{10}\right]$. The CRS used in conjunction with traditional instructional methods has the ability to significantly engage all students in even very large lecture classes. Therefore a study was conducted to know whether CRS helps in increased attentiveness and thus improved learning of the students. Also it would help to know the perception of students with regard to the Class Response system effectiveness. 


\section{MATERIALS AND METHOD}

The activity was carried out during the lecture classes of Public Health. Public Health is a course of three months. There are three block exams one each at the end of one month. First block exam which was at the end of the first month was without using CRS. CRS was used in the second and third month with subsequent second and third block exams. Twelve lectures were taken each of one hour duration. CRS presentation was made either at the end of a lecture or in between the two lectures. There were 10-15 questions in each presentation. Most of the questions were MCQ with 3-5 options and few were Yes/No types. After taking the lecture, CRS presentation was given. One question was flashed and the students had to use their clickers to click their response. The clickers were distributed to them before the lecture. The LCD screen would show the polling result, when all the students had finished polling which would take a minute, then the polling was stopped with one mouse click by the instructor. The clicks were anonymous and the students were free to click whichever response they wanted. Once they had clicked for one response, they could not click for the second time. Even if they clicked, their answers would not be added to the polling. With the next click of the instructor, the screen would graphically show how many students opted for each response. With the subsequent click the correct answer would be highlighted. The students would come to know the correct answer at that moment. Each one of them would know for themselves whether their response was correct or not. Then there would be discussion over the responses. If there was a lot of confusion, in a minutes' time the original lecture presentation slide reference could be shown again to the students to clarify their mistakes. After the presentation, the data of the whole CRS was saved to see the average correct responses.

Likert scale to get student feedback was prepared by the Course Director and validated by senior faculty members after which it was pilot tested with a few students and then modifications were done accordingly. It had 21 statements with 5 options (Strongly Agree, Agree, Neither agree nor disagree, Disagree, Strongly Disagree). There were 3 subjective questions about advantages, drawbacks and suggestions for use of turning point sessions. It was administered to the students at the end of all the CRS sessions were over after taking informed consent. Data was entered and analyzed in SPSS. Average correct responses for each question were noted for CRS. Chi square test was used to test the associations. A p value less than 0.05 was considered statistically significant.

\section{RESULTS AND DISCUSSION}

\section{CRS responses:}

The average percentage of correct responses in the CRS sessions was $77.15 \pm 10.34$. It was almost same in all the lectures. As the lectures proceeded, it did not increase. It was dependent 
on how many answers were opted correctly by all the students. The polling ranged from 98$100 \%$. The few missing polls would be the clickers whose radiations were not reaching the computer. Almost all the students would click their responses. In Block 1 exam where CRS was not used $75 \%$ students passed and 25\% failed. In Block 2 where CRS was used, 98.6\% students passed and 1.4\% only failed. In Block 3 also where CRS was used, 95.8\% students passed and $4.2 \%$ failed. Failure rate decreased with the implementation of CRS. This difference was statistically significant (Chi square $=26.215, \mathrm{p}=0.000$ ). Students who got more than $80 \%$ grades were $43 \%$ in block 1 (where no CRS was used) compared to $77 \%$ in Block 2 and $83 \%$ in Block 3. More no. of students got higher grades when CRS was used. This difference was statistically significant (Chi square $=31.6, \mathrm{p}=0.000)$.

\section{Ease of use:}

Response rate of the students to the feedback questionnaire was $96 \% .98 .6 \%$ of students agreed that it was simple and easy to use. 59.4\% disagreed that it takes a lot of time whereas $20.3 \%$ found it time consuming. $89.9 \%$ disagreed that they clicked the answers for fun and $97.1 \%$ agreed that they clicked the answers seriously to know whether their response was correct or not. $87 \%$ and $76.1 \%$ each disagreed that it made the class boring or stressful. $86.6 \%$ disagreed that the intervention was unnecessary. In fact $85.1 \%$ agreed that it made the class enjoyable.

\section{Effectiveness of CRS:}

$87 \%$ of students agreed that it aroused their interest in the class and $79.7 \%$ said that it made them more attentive during the lecture. $89.7 \%$ each were of the opinion that it helped them in memorizing the key points in the lecture and improved their knowledge more than other routine teaching methods used. 94\% agreed that it helped them in doing self-assessment as to how much they know and where they went wrong. 91.3\% agreed that maximum number of times the answers they clicked were correct. $79.1 \%$ agreed that it encouraged discussion over the wrongly answered questions. $77.6 \%$ each agreed that it encouraged them to participate during the teaching sessions and created a relaxed atmosphere in the class. $68.7 \%$ agreed that it helped them to interact with the teacher. $49.3 \%$ agreed that it stimulated them to read the topic after the class.85.1\% agreed that it helped them in recalling key points when they sat back to revise the lecture after the class. $70.1 \%$ agreed that it helped in improving their grades in the block exam. $45.5 \%$ of students rated the overall effectiveness of turning point as excellent, $40.9 \%$ as good and $10.6 \%$ as adequate; only $3 \%$ found it poor.

\section{Advantages and drawbacks of CRS:}

When asked about the advantages of the CRS, 10 said that it made them more attentive during the class. It highlighted the important points (12), helped to recall the important points even during the exams (15), helped to concentrate in the lecture (12), helped to know where mistakes 
were made and cleared them with explanations (5), and helped them to focus on main points while studying (6 responses). There were 5 responses that it made the class interesting and 2 responses that it helped to interact with the teacher. There were 13 responses that it was time consuming and 8 said that there were no drawbacks. There was a limited time for the session (1 response). It was used for fun (1 response).

\section{Suggestions for future use of CRS:}

CRS should be used for other subjects (14), should be used for exam reviews and conduction of final evaluation ( 3 each). There were 5 responses that it should be used for more difficult questions. Three responded that each student should be given a remote with his ID and it should be used to give report at the end of the block with regards to percentage of his correct responses. There were 2 responses that it should be given some percentage in the grades to increase the overall attendance of the students in the class.

\section{DISCUSSION}

Majority of the students believed that CRS was easy to use and made the class enjoyable; it made them attentive in the class and increased their concentration. The average percentage of correct responses in the turning point session was $77.2 \%$ showing that it really made the students attentive in the class and they concentrated on the content of the lecture. These findings are consistent with studies that have been published describing the use of CRS in other teaching contexts $\left[{ }^{11-13}\right]$.The questions flashed in the turning point were based on the lecture, so the students would attentively listen to the teacher so as to answer correctly. In fact $91 \%$ found that they answered turning point questions correctly. The ones who got wrong answers believed that it helped them to have discussion over the wrong concepts. Most of the students $(89.7 \%)$ found that it helped them in memorizing the key points in the lecture which helped them to recall it even when they studied on their own. The key points would give them a structure for their lecture and also prepare them for exam. There have been many reviews published exploring the cost, use and effect of ARS in the broader education literature [ $\left.{ }^{14-16}\right]$.

$77.6 \%$ agreed that it encouraged them to participate during the teaching sessions. It has been reported that student participation approaches $100 \%$ in class sessions where CRS are used due in part to anonymity, ease of use, and the ability to see how many others answered in the same way $\left[{ }^{17}\right]$. As with the many advantages the students noted with regards to CRS helping them in making attentive in the class and improving their learning in otherwise monotonous lectures, it goes without saying why they recommended it for other faculties and all the subjects.

Many (70\%) believed that it even helped them in improving the grades in the block exam. So it was not only a short recall, instead seeing their correct responses would give them confidence and wrong answers would initiate discussion. While comparing the grades of the students, in 
the block wherein CRS was used, more students scored higher grades and less students failed as compared to previous block where CRS was not used. But the topics may have made a difference in the two blocks. In the block where CRS was not being used, there is a clear picture that it did not have any scope of knowing what is going wrong in student's mind which needs to be clarified. In comparison when CRS was used, the teacher would know from the CRS responses where the students were going wrong and would discuss them in the class itself. Flashing questions at the end of the lecture would also act as a revision of key points of the lecture and thus would help them to recall it at the time of exams. Keeping these facts in mind, CRS really might have affected the grades towards better.

CRS can achieve positive results for participants $\left[{ }^{11}\right]$ and knowledge outcomes $\left[{ }^{13}\right]$. An increase of at least a $10 \%$ in knowledge assessment scores for the CRS group has been demonstrated $\left[{ }^{18,19}\right]$. Previous studies hypothesized that increased interaction, rather than the actual technology, may be the mechanism by which CRS positively affects student achievement $\left[{ }^{20}\right]$. As the whole process was anonymous, nobody would feel embarrassed to answer wrongly and would remember those mistakes forever. It was observed that learning is significantly improved when students received corrective feedback for incorrect answers $\left[{ }^{17}\right]$. It has been reported that immediate feedback resulted in more learning than delayed feedback $\left[{ }^{2}\right]$.

\section{CONCLUSION}

Students felt that use of CRS made them attentive in the class and increased their concentration. It created a platform for the students to interact with the teacher and clarify their concepts in the class itself. It helped them in memorizing the key points in the lecture which helped them to recall it even when they studied on their own. It even helped them in improving the grades in the block exams. CRS is effective and can be used in conjunction with didactic lectures for a rich experience for students on active learning, better understanding and improved knowledge outcomes.

\section{ACKNOWLEDGEMENT}

The author would like to acknowledge the FAIMER (Foundation for Advancement of International Medical Education and Research) faculty who supported in the project idea during author's FAIMER fellowship program.

\section{REFERENCES}

1. Judson E, Sawada D. Learning from past and present: Electronic response systems in college lecture halls. J Comput Math Sci Teach. 2002;21(2):167-181.

2. Abrahamson L. 2006. A brief history of networked classrooms: Effects, cases, pedagogy, and implications. In: Banks DA, editor. Audience response systems in higher education: Applications and cases. Hershey, PA: Information Science Publishing. p 25. 
3. Kay RH, LeSage A. A strategic assessment of audience response systems used in higher education. Australas J Educ Technol. 2009;25(2):235-249.

4. Broussard, B. To click or not to click: Learning to teach to the microwave generation. Nurse Education in Practice. 2012; 12:3-5.

5. Crouch, C. H., \& Mazur, E. Peer instruction: Ten years of experience and results. American Journal of Physics. 2001; 69:970-977.

6. Kolikant, Y. B.-D., Drane, D., \& Calkins, S. "Clickers" as catalysts for transformation of teachers. College Teaching. 2010; 58:127-135.

7. Draper, S. W., \& Brown, M. I. Increasing interactivity in lectures using an electronic voting system. Journal of Computer Assisted Learning. 2004; 20:81-94.

8. Shulman, L. S. Pedagogies of uncertainty. Liberal Education. 2005; 91:18-25.

9. O’Donoghue, M., Jardine, R., \& Rubner, G. Developing a hierarchy of clicker use for teaching and learning from models of dialogue analysis. Proceedings of World Conference on Educational Multimedia, Hypermedia and Telecommunications. 2010; 2105-2114.

10. Boyle, J. T., \& Nicol, D. J. Using classroom communication systems to support interaction and discussion in large class settings. Research in Learning Technology. 2003;11(3).

11. Caldwell JE. Clickers in the large classroom: Current research and best-practice tips. CBE Life Sci Educ. 2007;6(1):9-20.

12. Roschelle J, Penuel WR, Abrahamson L. The networked classroom. Educ Leadersh. 2004; 61(5):50-54.

13. Fies C, Marshall J. Classroom response systems: A review of the literature. J Sci Educ Technol. 2006;15(1):101-109.

14. Simpson V, Oliver M. Electronic voting systems for lectures then and now: A comparison of research and practice. Australas J Educ Technol. 2007; 23(2):187-208.

15. Cain J, Robinson E. A primer on audience response systems: Current applications and future considerations. Am J Pharm Educ. 2008; 72(4):77.

16. MacArthur JR, Jones LL. A review of literature reports of clickers applicable to college chemistry classrooms. Chem Educ Res Pract . 2008;9(3):187-195.

17. Guthrie R, Carlin A. 2004. "Waking the Dead: Using interactive technology to engage passive listeners in the classroom." Proceedings of the Tenth Americas Conference on Information Systems, New York NY, 1-8. 
18. Elashvili A, Denehy GE, Dawson DV, Cunningham MA. Evaluation of an audience response system in a preclinical operative dentistry course. J Dent Educ. 2008;72(11):1296-1303.

19. Rubio EI, Bassignani MJ, White MA, Brant WE. Effect of an audience response system on resident learning and retention of lecture material. Am J Roentgenol. 2008.; 190(6): 319-322.

20. Poulis J, Massen C, Robens E, Gilbert M. Physics lecturing with audience paced feedback. Am J Phys. 1998; 66(5):439-441.

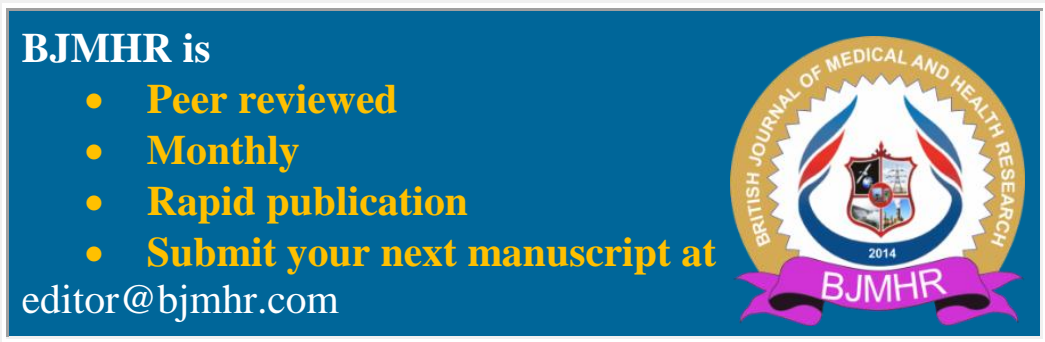

